\title{
A Study of normal variation in lumbosacral angle in asymptomatic patients attending orthopaedic out-patient department of a medical college hospital, Telangana
}

\author{
Ashok Kumar Jha ${ }^{1}$, Chintapeta Ravi ${ }^{2, *}$ \\ ${ }^{1}$ Assistant Professor, ${ }^{2}$ Associate Professor, Dept. of Orthopaedics, Mahavir Institute of Medical Sciences, Vikarabad, Telangana, \\ India
}

*Corresponding Author:

Email: chintapeta.ravi@gmail.com

\begin{abstract}
Introduction: The Lumbosacral angle (LSA), is the angle formed between a line across the plane of the superior margin of the sacrum and a horizontal line. Various literature and studies around the world shows wide normal variation in LS angle, ranging from $32^{0}$ to $44^{0}$. Abnormal variation in LS angle is commonly associated with low back pain. Hence research involving study of normal variation of LSA in different ethnic population plays a significant role. In Indian scenario very few studies are available, especially from rural population, to know up to what extent, variation in LS angle is normal. Hence, the present study attempts to study the normal variation in LSA in rural population of Telangana.

Materials and Methods: A descriptive study of normal LSA variability, involving 100 asymptomatic subjects between the age group of 20-60 years was carried out in orthopedic department of Medical College hospital, Telangana. Ferguson's technique was employed for calculation of LSA.

Results: In this study variation of LSA ranges from $28^{\circ}$ to $60^{\circ}$. Overall average LSA was $34^{0}$. Females have greater average LSA as compared to males.

Conclusion: Results of the present study show variability when compared to other similar studies, which further strengthen the fact that normal variation in LSA differs among different region and races; hence results of the present study will be a useful tool to health care providers for treating different spinal disorders of rural Telangana population.
\end{abstract}

Keywords: Lumbosacral angle (LSA), Ferguson technique, Lumbar lordosis, LSA Variation, Spinal maturity.

\section{Introduction}

Lumbar lordosis is anteriorly convex curvature of the lumbar spine to compensate for the inclination of the sacrum and restores an upward orientation. ${ }^{1}$ The development of lumbar lordosis in human spine is a result of evolutionary mechanisms occurring during the process of attaining bipedal gait and erect posture. ${ }^{2}$ During the process of embryonic development in humans, little or no lumbar lordosis is demonstrated. ${ }^{3}$ The extent of lumbar lordosis coincides with the stages of bipedal gait and increases from infancy to adulthood. Lumbar lordosis continues to develop till the completion of spinal growth, usually between the age group of 13 to 18 years. ${ }^{4}$ A delay in the development of the lumbar lordosis may be caused by growth retardation. ${ }^{5}$

The lumbosacral curvature of the vertebral column has a special function in terms of its mobility and weightbearing. ${ }^{6}$ Development of any abnormality in this curvature leads to symptoms ranging from mild discomfort to severe back pain, thus highlighting the importance of this curvature and its normal variability. Various methods have been used for the measurement of this curve, they include goniometry ${ }^{7,8}$ radiography ${ }^{9-}$ 13 flexible rulers, ${ }^{14-18}$ software methods, ${ }^{19}$ spinal mouse, ${ }^{20}$ and inclinometer. ${ }^{21,22}$ Of all these methods, radiography remains the gold standard and lordotic measurement can accurately be measured in a supine, lateral lumbosacral spine radiograph. ${ }^{23-25}$ The lumbosacral angle (LSA), one of the clinically important radiographic angles related to this curve is commonly measured to evaluate the biomechanical factors linked with lower back pain ${ }^{6}$, and is frequently measured by Ferguson's technique. ${ }^{26,27}$

LSA, also called as 'sacro-horizontal angle', the 'sacral angle' or the 'Ferguson's angle', is defined as " the angle formed between a line across the plane of the superior margin of $\mathrm{S}_{1}$ and a horizontal line",,28 or the angle formed between the "superior surface of the sacrum and the horizontal plane". ${ }^{6,29}$ Various research studies show wide normal variation in LSA in asymptomatic patients, ranging from $32^{0}$ to $44^{0}$. 6, 23, 26, ${ }^{30,} 31$ With this wide variation in LSA, there is still a considerable discussion in current literature as to what constitute a normal variation. An increased angle suggests a mechanical factor in producing low back pain by increasing the shearing and compressive forces on the articular facets at the lumbosacral junction. ${ }^{32}$ With this background, the present study attempts to evaluate normal variation of LSA in rural Telangana population, the results of which might be a useful tool for assessing spinal disorder and the treatment of lower back pain.

\section{Materials and Methods}

This study was conducted in orthopedic outpatient department (OPD) of a Medical College hospital, Vikarabad, Telangana. The study duration was two 
months from September 2017 to October 2017. Due Institutional ethical clearance was taken for the conduct of this study. Oral informed consent was taken from study subjects before their inclusion in this study. Confidentiality of study subject data is maintained. During the study period 100 patients were screened for LSA with following Inclusion and exclusion criteria.

\section{Inclusion Criteria:}

1. Patients attending Orthopedic OPD with complaints not related to back pain/disorder.

2. Patients with no history of back pain for more than 6 months.

3. Patients between the age group of 20-60 years.

\section{Exclusion Criteria:}

1. Patients less than 20 years or above 60 years.

2. Symptomatic back pain patients or patients who had history of back pain less than 6 months back.

Criteria/Methodology for L.S angle Calculation: Ferguson technique was employed for calculation of LSA in our study. Here X-ray of lumbo-sacral spine, anterior-posterior (AP) and lateral view of study subjects were taken. A-P view was taken with patient in supine position and lateral view was taken with patient in left decubitus position. Patient's hip and knees were flexed while taking both the views to relax the spinal muscles in order to avoid alteration of lumbo-sacral curve.

The processed film was mounted on the $\mathrm{x}$-ray film viewing box. A straight line is drawn tangent to the superior surface of the sacrum (AB line). Another straight line is drawn horizontal/parallel to the base of $\mathrm{x}$-ray film (AC). The angle formed at the intersection of line $\mathrm{AB}$ with $\mathrm{AC}$ is L.S angle (Fig-1) and is measured using a protractor.

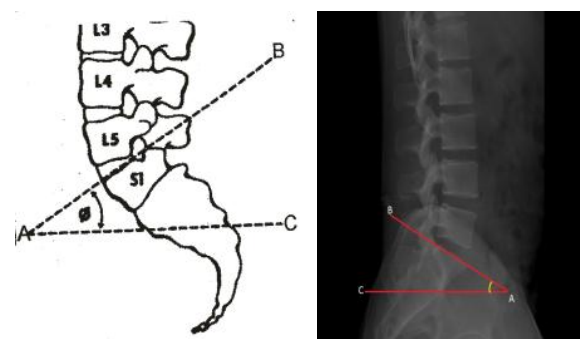

Fig. 1: Lumbosacral angle calculation (schematic and radiographic representation)

\section{Results}

Of 100 study subjects, 55 were males and 45 were females. Average LSA in female study subject was more than that of males. (Fig. 2)

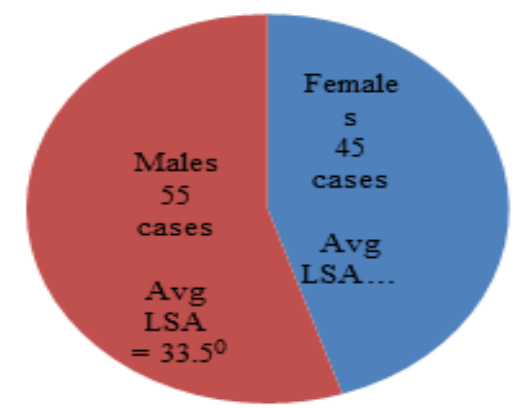

Fig. 2: Sex wise distribution of cases and mean LSA

Variation in LSA among study subject is depicted in table-1. As seen in table-1, no cases were reported for LSA variation between the range of $11-20^{\circ}$ and also in $61-70^{\circ}$ range. More than $50 \%$ study subject has normal LSA variation in the range of $31-40^{\circ}$, whereas least number of subjects $(5 \%)$ falls in $51-60^{\circ}$ range.

Table 1: Distribution of cases according to ranges of Lumbosacral angle

\begin{tabular}{|c|c|}
\hline $\begin{array}{c}\text { Lumbosacral } \\
\text { Angle }\left(^{\circ}\right)\end{array}$ & $\begin{array}{c}\text { Total No. of Cases } \\
(\boldsymbol{\%})\end{array}$ \\
\hline $11-20^{\circ}$ & ---- \\
\hline $21-30^{\circ}$ & $33(33 \%)$ \\
\hline $31-40^{\circ}$ & $52(52 \%)$ \\
\hline $41-50^{\circ}$ & $10(10 \%)$ \\
\hline $51-60^{\circ}$ & $5(5 \%)$ \\
\hline $61-70^{\circ}$ & --- \\
\hline
\end{tabular}

Table 2 depicts age wise distribution of study subjects. LSA varies from $28^{0}$ to $60^{\circ}$ in study cases. Mean LSA is maximum $\left(34.5^{\circ}\right)$ in 51-60 year age group. In the present study, the overall average LSA of all 100 subjects was $34^{0}$.

Table 2: Agewise distribution of cases and mean lumbosacral angle in different age groups

\begin{tabular}{|c|c|c|c|c|}
\hline S. No. & $\begin{array}{c}\text { Age Group } \\
\text { (years) }\end{array}$ & $\begin{array}{c}\text { No. of } \\
\text { Cases }\end{array}$ & $\begin{array}{c}\text { Ranges of Lumbo-sacral } \\
\text { Angle in Degrees }\end{array}$ & $\begin{array}{c}\text { Mean } \\
\text { Lumbo-sacral Angle }\end{array}$ \\
\hline 1. & $21-30$ & 22 & $28-52^{\circ}$ & $33.6^{\circ}$ \\
\hline 2. & $31-40$ & 41 & $25-48^{\circ}$ & $34.4^{\circ}$ \\
\hline 3. & $41-50$ & 21 & $28-50^{\circ}$ & $33.5^{\circ}$ \\
\hline 4. & $51-60$ & 16 & $29-60^{\circ}$ & $34.5^{\circ}$ \\
\hline \multicolumn{6}{|r}{ Overall Mean Lumbo-sacral Angle } & $34^{\circ}$ \\
\hline
\end{tabular}


Though all 100 subjects were asymptomatic but 40 among them have significant radiological finding. Osteoarthritis is the commonest significant radiological finding in the present study.
Details of significant radiological findings in 40 study subjects along with comparison of similar findings with other studies were mentioned in Table 3.

Table 3: Radiological findings in study subjects and its comparison with similar studies

\begin{tabular}{|c|c|c|c|}
\hline 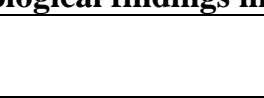 & $\begin{array}{c}\text { Present Study } \\
2017\end{array}$ & $\begin{array}{c}\text { Splithoff et al } \\
{ }_{(1953)}\end{array}$ & $\begin{array}{l}\text { Breck, Hillsman and } \\
{\text { Bason et } \text { al }^{33}(1944)}^{2}\end{array}$ \\
\hline $\begin{array}{l}\text { Number of } \\
\text { Roentgenogram }\end{array}$ & 100 & 100 & 450 \\
\hline $\begin{array}{l}\text { Transitional } \\
\text { vertebrae }\end{array}$ & 11 & 10 & $11 \%$ \\
\hline Spondylolisthesis & 1 & 3 & $3 \%$ \\
\hline Spinabifida & 4 & 6 & $6 \%$ \\
\hline Osteoarthritis & 24 & 22 & $21 \%$ \\
\hline
\end{tabular}

The following table (Table 4) gives a comparative analysis of the average lumbosacral angle (LSA) in various studies. In the present study, the overall average LSA of all 100 subjects was $34^{0}$.

Table 4: Comparison of various studies average L.S angle with present study

\begin{tabular}{|c|c|c|}
\hline S.No. & Authors (Year) & $\begin{array}{c}\text { Average } \\
\text { LSA }\end{array}$ \\
\hline 1. & Present study & $34^{\circ}$ \\
\hline 2. & Fernard $(1985)^{23}$ & $45.05^{\circ}$ \\
\hline 3. & Blackburne $(1977)^{30}$ & $32^{\circ}$ \\
\hline 4. & Splithoff $(1953)^{31}$ & $40^{\circ}-44^{\circ}$ \\
\hline 5. & Ferguson $(1949)^{26}$ & $34^{\circ}$ \\
\hline 6. & Friedman $(1946)^{34}$ & $43^{\circ}$ \\
\hline 7. & Von - Lackum $(1924)^{35}$ & $42.5^{\circ}$ \\
\hline
\end{tabular}

\section{Discussion}

In the present study, the average LSA in female population was greater than the males. This finding is similar to what Bryan et al and Amonoo Kuofi et al concluded in their studies. ${ }^{36,37}$ Greater LSA in females could be due to evolutionary changes adapted to assist pregnancy and hormonal changes during reproductive age. ${ }^{38}$ Vialle et al also observed a larger lordosis in females as compared to males, when measured by the Cobb angle. ${ }^{39}$ However Guldal et al concluded that in young individuals, male LSAs were greater than female LSA, whereas in older age group females have greater LSA than males. ${ }^{40}$

In the present study, the overall average LSA of all 100 subjects was $34^{0}$. Wide variations in the measurement of LSA are noted in different studies mentioned in Table 4. Von Lackum et al reported LSA value of $42.5^{\circ}$ in a study of 30 cadavers. ${ }^{35}$ Splithoff et al recorded $40-44^{\circ}$ as the largest number of lumbosacral angles in a prospective study of 100 subjects in the recumbent position. ${ }^{31}$ Bryan et al reported that it varies between $15^{\circ}$ and $25^{\circ}$ in the Caucasians in erect position and that females have higher values than males. ${ }^{36}$ Ferguson et al reported that when LSA exceeds $34^{\circ}$, an abnormality in stability exists between the lumbar and sacral spines. ${ }^{27}$ Troyanovich et al in their retrospective study of 50 normal healthy subjects in the erect posture recorded average LSA value of $39^{\circ} .{ }^{41}$ Maduforo et al reported a value of $36.0^{\circ}$ in a prospective study of 100 male subjects (aged 0-75 years) of Nigeria. 28 This wide variation of LSA in different studies emphasizes the role of ethnicity and different geographical region. Similar observation was also drawn by El Sayed et al, which concludes that the normal LSA values are of forensic importance due to observed racial, ethnic and regional variations. ${ }^{1}$

The lumbar lordosis begins to develop as an infant starts to stand, usually between 12 and 18 months of age. The completion of spinal growth occurs usually between 13 to 18 years. ${ }^{4}$ The study population in the present study is between 20-60 years thus indicating that all the subjects have completed spinal growth. Age wise distribution of the average LSA (Table 2) in the present study doesn't show much variation. Similar findings were also reported in Okpala et al study, where no significant variation of the LSA noted between the age groups 15 to 74 years. ${ }^{42}$ The reason for this may be the fact that the development of the lumbar lordosis reaches a plateau at spinal maturity., ${ }^{41}$ This fact is further strengthened by Abitol et al findings, where LSA was studied in 131 children ranging from birth to 5 years, here LSA increases from an average of 20 degrees at birth to an average of 70 degrees at the age of 5 years; it fairly remains at that level thereafter. ${ }^{2}$

Similar findings were noted in this present study, which established that in all the various age groups between 21 and 60 years (which were the smallest and the highest ages of the studied population), the mean LSA showed no significant difference between the groups, and this confirms that the development of lumbar lordosis reaches a level at spinal maturity, usually between 13 and 18 years. Hence, rather than age, the development of the LSA is more related to the progressive acquisition of erect posture and the ontogeny of bipedal locomotion. ${ }^{2}$ 
The shape of the lumbar lordosis has been reported to be a significant factor in the pathophysiology of low back pain. ${ }^{23,43}$ A wide range of normal values for LSA is documented in the literature, ranging from 32 degrees to 42 degrees. ${ }^{6,23,30,31,26}$ An increased angle suggests a mechanical factor in producing low back pain by increasing the shearing and compressive forces on the articular facets at the lumbosacral junction. ${ }^{32} \mathrm{An}$ increase in lordotic angle proportionally increases the shearing strain or stress in the anterior direction and shifts the centre of gravity anteriorly. From a biomechanical point of view, the accentuated lumbar lordosis is associated with an increased prevalence of low back pain. ${ }^{32}$ However Pate et al (1991) have stated that a wide variation of normal values for LSA in different studies makes it difficult to know the significance of decreased or increased LSA ${ }^{44}$ Thus this necessitates the need of regional and ethnic specific normal LSA value, which will be more useful for radiologist, orthopaedician and physiotherapist for the management of patients with low back pain. ${ }^{43}$ This present study was an attempt to address this concern.

\section{Conclusion}

The overall average LSA of 100 study subjects was $34^{0}$. The average LSA in females was greater than the males. The present study established that in all the various age groups between 21 and 60 years (which were the smallest and the highest ages of the studied population), the mean LSA showed no significant difference between the groups. This confirms that the development of lumbar lordosis reaches a level at spinal maturity, usually between 13 to 18 years. Furthermore, findings of the present study shows variability when compared to other similar studies, which further strengthen the fact that normal variation in LSA differs among different region and races; hence the results of the present study will be a useful tool to health care providers for treating different spinal disorders of rural Telangana population.

\section{References}

1. El Sayed S, Saab IM, EI Shishtawy M, et al. Morphometric study of the lumbosacral spine and some of its related angles in Lebanese adult females. IJAE 2014;119(2):92-105.

2. Abitbol MM.Evolution of the lumbosacral angle.Am $\mathbf{J}$ Phys Anthropol 1987;72:361-372.

3. Choufani E, Jouve JL, Pomero V, Adalian P, Chaumoitre K, Panuel M: Lumbosacral lordosis in fetal spine: genetic or mechanic parameter. J Spine Eur18:1342-1348, 2009.

4. Oliver J, Middleditch A. Functional Anatomy of the Spine. Oxford: Butterworth-Heinemann; 1998. Lumbar spine; pp. 36-58.

5. Reichmann S, Lewin T. The development of the lumbar lordosis. A post mortem study on excised lumbar spines. Arch Orthop Unfallchir. 1971;69:275-85.

6. Onyemaechi NOC. Evaluation of lumbar angles and their clinical correlates in a Nigerian population. Int J Res Med Sci 2016;4:2018-23.
7. Norkin CC, White DJ. Chicago: Am Acad Orthop Surg; 1965. Joint Motion: Method of Measuring and Recording; pp. 48-9.

8. Burdett RG, Brown KE, Fall MP. Reliability and validity of four instruments for measuring lumbar spine and pelvic positions. Phys Ther. 1986;66:677-84.

9. Cobb JR. Outline for the study of scoliosis. In: Thomson JE, Blount WP, editors. American Academy of Orthopaedic Surgeons, Instructional Course Lectures. Vol. 5. Ann Arbor: JW Edwards; 1948. pp. 261-75.

10. Troyanovich SJ, Harrison DE, Harrison DD, Holland B, Janik TJ. Further analysis of the reliability of the posterior tangent lateral lumbar radiographic mensuration procedure: Concurrent validity of computer-aided X-ray digitization. J Manipulative Physiol Ther. 1998; 21:4607.

11. Chernukha KV, Daffner RH, Reigel DH. Lumbar lordosis measurement. A new method versus Cobb technique. Spine (Phila Pa 1976) 1998;23:74-9.

12. Chen YL. Vertebral centroid measurement of lumbar lordosis compared with the Cobb technique. Spine (Phila $\mathrm{Pa}$ 1976) 1999;24:1786-90.

13. Hong JY, Suh SW, Modi HN, Hur CY, Song HR, Park JH. Reliability analysis for radiographic measures of lumbar lordosis in adult scoliosis: A case-control study comparing six methods. Eur Spine J. 2010; 19:1551-7.

14. Hart DL, Rose SJ. Reliability of a noninvasive method for measuring the lumbar curve. J Orthop Sports Phys Ther. 1986;8:180-4.

15. Youdas JW, Suman VJ, Garrett TR. Reliability of measurements of lumbar spine sagittal mobility obtained with the flexible curve. J Orthop Sports Phys Ther. 1995;21:13-20.

16. Rajabi R, Seidi F, Mohamadi F. Which method is accurate when using the flexible ruler to measure the lumbar curvature angle? Deep pint or midpoint of arch? World Appl Sci J. 2008;4:849-52.

17. Seidi F, Rajabi R, Ebrahimi TI, Tavanai AR, Moussavi SJ. The Iranian flexible ruler reliability and validity in lumbar lordosis measurements. World J. Sport Sci. 2009;2:95-9.

18. de Oliveira TS, Candotti CT, La Torre M, Pelinson PP, Furlanetto TS, Kutchak FM, et al. Validity and reproducibility of the measurements obtained using the flexicurve instrument to evaluate the angles of thoracic and lumbar curvatures of the spine in the sagittal plane. Rehabil Res Pract 2012. 2012:186156.

19. Babai E, Khodamoradi A, Mosavi Z, Bahari S. An innovative software method for measuring lumbar lordosis. Biol Res. 2012 3:204-13.

20. Lopez-Minarro PA, Muyor JM, Belmonte F, Alacid F. Acute effects of hamstring stretching on sagittal spinal curvatures and pelvic tilt. J Hum Kinet. 2012;31:69-78.

21. Souza Filho JC, Abras AC, Carvalho MT, Souza MG, Souza AT, Costa LO. Analysis of the interexaminer reliability of two clinical tests to measure the flexion range of motion of the lumbar spine. Acta Fisiatr. 2007; 14:214-8.

22. Macintyre NJ, Bennett L, Bonnyman AM, Stratford PW. Optimizing reliability of digital inclinometer and flexicurve ruler measures of spine curvatures in postmenopausal women with osteoporosis of the spine: An illustration of the use of generalizability theory. ISRN Rheumatol 2011. 2011:571698.

23. Fernand R, Fox DE. Evaluation of lumbar lordosis. A prospective and retrospective study. Spine 1985; 10:799803. 
24. Salisbury PJ, Porter RW. Measurement of lumbar sagittal mobility. A comparison of methods. Spine (Phila Pa 1976) $1987 ; 12: 190-3$.

25. Vrtovec T, Pernus F, Likar B. A review of methods for quantitative evaluation of spinal curvature. Eur Spine J. 2009; 18:593-607.

26. Ferguson AB. 2nd ed. New York: Paul B Hoeber, Inc; 1949. Roentgen Diagnosis of the Extremities and Spine;pp. 382-3.

27. Ferguson $\mathrm{AB}$. Clinical and roentgen interpretation of lumbosacral spine. Radiology. 1934;22:548-58.

28. Maduforo C, West O, Nwankwo N, et al. Study of the Lumbosacral angles of males in Port Harcourt, SouthSouth Nigeria. The Nigerian Health Journal 2012;12(1):22-4

29. Wiltse LL, Winter RB. Terminology and measurement of spondylolisthesis. J Bone Joint Surg Am. 1983; 65:76872.

30. Blackburne JS, Velikas EP (1977) Spondylolisthesis in children and adolescents. J Bone Joint Surg Br 59:490494.

31. Splithoff CA. Lumbosacral junction; roentgenographic comparison of patients with and without backaches. J Am Med Assoc. 1953;152:1610-3.

32. Yochum, T. R.; Rowe, L. J. Essentials of Skeletal Radiology 1987; Vol I: 91.

33. Breck, Hillsman and Bason. Lumbosacral roentgenograms of 450 consecutive applicants for heavy work. Annals of Surgery July 1944;120(1):88-93.

34. Friedman M M, Fischer FJ, and Van Demark RE. Lumbosacral Roentgenograms of 100 Soldiers. American Journal of Roentgenology and Radium Therapy, 1946:55, 292.

35. Von Lackum HI. Lumbosacral region. J Am Med Assoc. 1924; 82:1109-14.

36. Bryan GJ. Diagnostic Radiography, A Concise Practical Manual. 4th ed. London: Churchill Livingstone; 1987. Lumbar vertebrae; p. 152.

37. Amonoo-kuofi HS. Changes in the lumbosacral angle, sacral inclination and the curvature of the lumbar spine during aging. Acta Anatomica (Basel) 1992;145(4):3737.

38. Bailey JF, Sparrey CJ, Been E, Kramer PA. Morphological and postural sexual dimorphism of the lumbar spine facilitates greater lordosis in females. $\mathbf{J}$ Anat. 2016 Jul; 229(1):82-91.

39. Vialle R, Levassor N, Rillardon L, Templier A, Skalli W, Guigui P. Radiographic analysis of the sagittal alignment and balance of the spine in asymptomatic subjects. J Bone Joint Surg Am. 2005;87: 260-267.

40. Guldal Funda Nakipoglu, MD, Aynur Karagoz, MD, and Nese Ozgirgin, MD .The Biomechanics of the Lumbosacral Region In Acute And Chronic Low Back Pain Patients . Pain Physician 2008;11:505-511.

41. Troyanovich SJ, Cailliet R, Janik TJ, Harrison DD, Harrison DE. Radiographic mensuration characteristics of the sagittal lumbar spine from a normal population with a method to synthesize prior studies of lordosis. J Spinal Disord. 1997;10:380-6.

42. Okpala F. Measurement of Lumbosacral Angle in Normal Radiographs: A Retrospective Study in Southeast Nigeria. Annals of Medical and Health Sciences Research. 2014;4(5):757-762. doi:10.4103/21419248.141548.

43. Lord MJ, Small JM, Dinsay JM, Watkins RG. Lumbar lordosis. Effects of sitting and standing. Spine 1997;22:2571- 2574.
44. Pate D. Stability of the Lumbar Spine. Dynamic Chiropractice 1991;9(11):1-3. 